$\mathrm{DOI}$

\title{
ЛЕЧЕНИЕ ДЕТЕЙ С ХРОНИЧЕСКИМ БРОНХИТОМ
}

\author{
๑А. М. Шамсиев, Л. А. Мухамадиева, Ш. А. Юсупов, Д. Т. Раббимова \\ Самаркандский государственный медицинский институт
}

РЕЗЮМЕ. Для улучшения результатов лечения детей с хроническим бронхитом было обследовано 27 детей с этой патологией и 22 здоровых ребенка для контрольной группы. Детям с хроническим бронхитом во время бронхоскопии произведена аутотрансплантация макрофагальных клеток респираторного тракта со стимуляцией полиоксидонием. Эффективность данного метода была доказана улучшением показателей лаважной жидкости и иммунологического статуса детей до и после лечения.

КЛЮЧЕВЫЕ СЛОВА: эндобронхит, полиоксидоний, альвеолярные макрофаги, иммуноглобулины, лимфоциты.

Актуальность проблемы. Хронические воспалительные болезни легких являются актуальной проблемой педиатрии, поскольку их частота в последние годы нарастает, а клинические проявления характеризуются тяжестью течения и ранней инвалидизацией больных $[1,10,11]$.

Сложность проблемы хронического бронхита в определенной степени отражена в Международной статистической классификации болезней и проблем, связанных со здоровьем (10-й пересмотр ВОЗ, 1995), где значатся разные наименования (варианты) хронического бронхита: простой, слизисто-гнойный, смешанный и др.), которые клинически трудно различимы, что вызывает определенные сложности в повседневной практике [5, 9].

Нарушение дренажной функции бронхов способствует возникновению инфекционного процесса, активность и рецидивы которого в значительной степени зависят от местного иммунитета бронхов и развития вторичной иммунологической недостаточности $[3,5,13]$.

Хронический бронхит у детей может быть проявлением целого ряда других бронхолегочных патологий (приобретенных, врожденных, наследственных), дифференциация которых нередко представляет определенные сложности [4-8, 12].

Цель исследования - улучшение результатов лечения детей с хроническим бронхитом для предотвращения прогрессирования болезни и снижения частоты обострений.

Материал и методы исследования. Обследовано 27 детей с хроническим бронхитом и 22 здоровых ребенка, в возрасте от 3 до 15 лет. Больным были проведены следующие исследования: определение числа Т-лимфоцитов и их субпопуляций (CD3+, CD4+, CD8+), естественных киллеров (CD16+), В-лимфоцитов (CD20+) модифицированным методом Гурарий Н. И. (1981) [2]; концентрацию сывороточных иммуноглобулинов A, G, М в периферической крови по мето- ду Manchini G. et. al (1965); Для цитологического анализа бронхоальвеолярно-лаважной жидкости (БАЛЖ) собирали 5 - 6 порций бронхиальных смывов. После тщательного перемешивания аспирированную жидкость подвергали цитологическому анализу: разводили физиологическим раствором 1:20 и подсчитывали клеточные элементы в 25 больших квадратах камеры Горяева. Соотношение альвеолярных макрофагов, нейтрофильных гранулоцитов и лимфоцитов изучали в мазках из центрифугата бронхоальвеолярного смыва, окрашенных по Романовскому-Гимзе, на основании подсчета 100 клеток.

Результаты и их обсуждение. Аутотрансплантацию макрофагальных клеток респираторного тракта (АМКРТ) со стимуляцией полиоксидонием осуществляли следующим образом. Во время бронхоскопии из устьев сегментарных бронхов донорского участка без признаков эндобронхита производили лаваж 0,85 \% раствором хлорида натрия и полиоксидония в дозе 0,1 мг/кг, затем субстрат вводили в бронхи пораженной зоны после их промывания физиологическим раствором до появления чистых вод.

В первую группу вошли 12 детей, которые получили традиционное лечение. Во вторую группу вошли 15 детей, которым была проведена аутотрансплантациямакрофагальныхклетокреспираторного тракта со стимуляцией полиоксидонием.

Как следует из представленных данных (табл. 1), у детей 1-й группы, под влиянием базисного лечения показатели иммунной системы изменились незначительно, большинство показателей иммунного статуса либо практически не изменились, либо изменились, но разница до и после лечения статистически была недостоверной ( $\mathrm{P}>0,05)$.

Динамика иммунологических показателей у больных под влиянием АМКРТ со стимуляцией полиоксидонием показали значительную эффективность терапии, по сравнению с детьми, 
Огляди літератури, оригінальні дослідження, погляд на проблему

получавшими традиционное лечение. При этом отмечалось достоверное повышение содержания Т-лимфоцитов (CD3+,\%) до $(55,9 \pm 0,2) \%$ по отношению к исходным данным $(P<0,001)$, больше во 2-ой группе, чем 1-ой группе. Субпопуляции CD4+-лимфоцитов, также повышались после ле- чения во 2-ой группе по отношению к исходным данным ( $\mathrm{P}<0,001)$. Субпопуляции лимфоцитов, несущие маркеры CD8+, также имели положительную динамику, при сравнении показателей

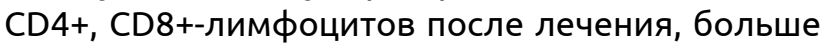
во 2-ой, чем 1-ой группе больных $(P<0,01)$.

Таблица 1. Иммунологические показатели детей с хроническим бронхитом, получавших аутотрансплантацию

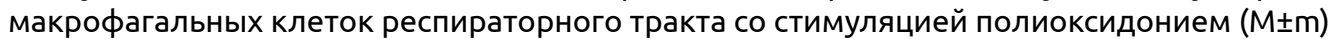

\begin{tabular}{|c|c|c|c|c|c|}
\hline \multirow{2}{*}{$\begin{array}{c}\text { Анализируемые } \\
\text { показатели }\end{array}$} & \multirow{2}{*}{$\begin{array}{c}\text { Практически } \\
\text { здоровые дети } \\
\text { n=22 }\end{array}$} & \multicolumn{2}{|c|}{ I группа $n=12$} & \multicolumn{2}{|c|}{ II группа n=15 } \\
\hline & & до лечения & после лечения & до лечения & после лечения \\
\hline Лимфоциты, \% & $34,6 \pm 2,3$ & $31,9 \pm 0,6$ & $32,2 \pm 1,1$ & $31,8 \pm 0,2$ & $33,1 \pm 1,2$ \\
\hline $\mathrm{CD}^{+}, \%$ & $61,5 \pm 2,2$ & $45,6 \pm 0,6$ & $46,8 \pm 2,4$ & $44,6 \pm 2,4$ & $55,9 \pm 0,2$ \\
\hline $\mathrm{CD}^{+}, \%$ & $39,2 \pm 2,1$ & $22,8 \pm 2,2$ & $26,9 \pm 2,1$ & $23,0 \pm 2,1$ & $37,1 \pm 1,5$ \\
\hline $\mathrm{CD}^{+}, \%$ & $19,5 \pm 1,8$ & $14,8 \pm 0,3$ & $15,9 \pm 1,3$ & $14,8 \pm 0,5$ & $19,1 \pm 0,1$ \\
\hline ИРИ (CD4/ CD8) & $2,0 \pm 0,1$ & $1,5 \pm 0,4$ & $1,7 \pm 0,4$ & $1,6 \pm 0,2$ & $1,9 \pm 0,3$ \\
\hline CD16,$\%$ & $10,2 \pm 1,3$ & $17,9 \pm 1,8$ & $16,6 \pm 1,2$ & $17,8 \pm 1,4$ & $11,0 \pm 0,7$ \\
\hline Фагоцитоз, \% & $58,5 \pm 2,3$ & $46,4 \pm 1,2$ & $49,6 \pm 2,5$ & $46,0 \pm 1,6$ & $56,8 \pm 1,3$ \\
\hline ЦИК & $1,01 \pm 0,1$ & $2,1 \pm 0,2$ & $1,6 \pm 0,6$ & $1,8 \pm 0,2$ & $1,2 \pm 0,2$ \\
\hline $\mathrm{CD} 20^{+}, \%$ & $16,4 \pm 0,5$ & $37,2 \pm 1,8$ & $34,6 \pm 2,1$ & $37,2 \pm 1,2$ & $22,8 \pm 1,6$ \\
\hline $\operatorname{lgG}, \mathrm{Mr} / \%$ & $938,3 \pm 17,6$ & $1836,4 \pm 32,8$ & $1759,2 \pm 23,2$ & $1788,6 \pm 31,6$ & $1356,2 \pm 20,8$ \\
\hline $\operatorname{lgA}, \mathrm{Mr} / \%$ & $107,97 \pm 3,6$ & $179,6 \pm 3,4$ & $169,6 \pm 4,1$ & $156,4 \pm 3,8$ & $121,2 \pm 3,4$ \\
\hline $\operatorname{lgM}, \mathrm{Mr} / \%$ & $90,7 \pm 2,8$ & $206,8 \pm 4,4$ & $199,9 \pm 4,1$ & $179,8 \pm 4,2$ & $126,8 \pm 3,4$ \\
\hline
\end{tabular}

Примечание: а - достоверность различий показателей 1-ой группы до и после лечения; 6 - достоверность различий показателей 2-ой группы до и после лечения.

Соответственно индекс иммунной регуляции в группе больных, получивших АМКРТ со стимуляцией полиоксидонием, приближался к нормативным показателям, в отличие от показателей ИИР в І-группе, где он оставался стабильно низким.

После лечения показатели CD16+ лимфоцитов у детей 2-ой группы достоверно отличались от 1 -ой группы после лечения $(16,6 \pm 1,2) \%(P<0,01)$.

Уровень CD20+-лимфоцитов у больных 2-ой группы достоверно $(P<0,001)$ снизился до $(22,8 \pm 1,6) \%$ по отношению к исходным данным.

Использование АМКРТ со стимуляцией полиоксидонием у детей с хроническим бронхитом положительно повлияло на иммунологические показатели детей.
Результаты эндобронхиальной цитограммы при хроническом бронхите у детей в зависимости от вида аутотрансплантации представлены в таблице 2. Как видно из представленных данных, при АМКРТ с физиологическим раствором было незначительное улучшение показателей после проведения аутотрансплантации макрофагальных клеток респираторного тракта, по сравнению с детьми 2-ой группы. Все показатели до лечения указывают на выраженный воспалительный процесс в бронхах и представляют диагноз гнойного эндобронхита несомненным.

При АМКРТ со стимуляцией полиоксидонием показатели до лечения схожи с показателями предыдущей группы: в цитограмме преоблада-

Таблица 2. Эндобронхиальная цитограмма при хроническом бронхите у детей в зависимости от вида лечения $(\mathrm{M} \pm \mathrm{m})$

\begin{tabular}{|l|c|c|c|c|}
\hline $\begin{array}{c}\text { Клеточные } \\
\text { элементы }\end{array}$ & Нейтрофилы (\%) & Лимфоциты (\%) & $\begin{array}{c}\text { Альвеолярные } \\
\text { макрофаги (\%) }\end{array}$ & Цитоз (109/л) \\
\hline Норма & $9,6 \pm 1,5$ & $8,3 \pm 1,6$ & $82,1 \pm 3,1$ & $0,8 \pm 0,03$ \\
\hline 1 группа АМКРТ с физиологическим раствором $\mathrm{n}=12$ & $15,2 \pm 3,2$ & $4,2 \pm 1,2$ \\
\hline До лечения & $79,8 \pm 1,6$ & $4,8 \pm 0,8$ & $18,6 \pm 3,1$ & $2,2 \pm 0,2$ \\
\hline После лечения & $72,2 \pm 3,6$ & $9,2 \pm 1,6$ & $19,6 \pm 2,0$ & $2,8 \pm 0,5$ \\
\hline 3 группа АМКРТ со стимуляцией полиоксидонием $\mathrm{n}=15$ & $9,6 \pm 0,6$ & $32,0 \pm 2,8$ & $1,8 \pm 0,3$ \\
\hline
\end{tabular}


Огляди літератури, оригінальні дослідження, погляд на проблему

ют нейтрофильные лейкоциты, снижено количество альвеолярных макрофагов и увеличено количество цитоза. После лечения АМКРТ со стимуляцией полиоксидонием отмечается увеличение количества альвеолярных макрофагов до $(32,0 \pm 2,8) \%$, снижается количество нейтрофилов до $(54,8 \pm 2,5) \%$, увеличивается количество лимфоцитов до $(12,1 \pm 2,0) \%$ и снижается количество цитоза до $(1,8 \pm 0,3) \%$.

Выводы. Анализ показателей БАЛЖ у детей, получавших лечение ауторансплантацией макрофагальных клеток респираторного трак- та со стимуляцией полиоксидонием, показал эффективность дифференцированного метода лечения, что выражалось в снижении количества нейтрофильных лейкоцитов в 1,4 раза, увеличении количества альвеолярных макрофагов в 3,0 раза, увеличении количества лимфоцитов 1,2 раза, снижении количества цитоза в 2,9 раза по сравнению с детьми контрольной группы. Это приводит к усилению фагоцитоза, что указывает на регрессию воспалительного процесса в бронхах и переход гнойного эндобронхита в катаральный.

\section{ЛИТЕРАТУРА}

1. Бубнова Н. И. Хронические неспецифические заболевания легких у детей: в кн. «Клеточная биология легких в норме и при патологии» (под редакцией Ерохина В. В., Романовой Л. К.) - М., 2000. - С. 351-357.

2. Гурарий Н. И. Количественный анализ Т- и В-лимфоцитов и их антигенсвязывающих субпопуляций у здоровых и больных пневмонией детей : автореф. дисс. на соискание ученой степени канд. мед. наук. - Самарканд, 1981. - 23 с.

3. Калуцский П. В., Шварцкопф Е. С., Окушко Р. В. // Педиатрия. - 2011. - Т. 90, № 1. - С. 124-126.

4. Капранов Н. И. Фармакотерапия при бронхолегочных поражениях у детей, больных муковисцидозом : руководство по фармакотерапии в педиатрии и детской хирургии / Н. И. Капранов. - М., 2002. - 267 с.

5. Кушелевская О. В. Частота микоплазменной и хламидийной инфекции у детей с врожденными пороками развития легких и бронхов / О. В. Кушелевская, И. В. Зубкова, Т.Б. Сенцова //Вопросы совр. педиатрии.2006. - T. 5, № 1. - С. 321.

6. Латыпова Ш. А. Роль NO-ергической системы в формировании рецидивирующих форм бронхитов у детей и принципы их лечения : автореф. дисс. на соискание ученой степени канд. мед. наук. - Ташкент, 2011.

7. Палеев Н. Р. Хронический бронхит / Н. Р. Палеев, В. А. Ильченко // Болезни органов дыхания : в кн.
Руководство по внутренним болезням (под редакцией Палеева Н. Р.). - М. : - Медицина, 2000. - 287 с.

8. Рачинский С. В. Место хронической пневмонии и хронического бронхита в бронхолегочной патологии у детей / С. В. Рачинский, В.К. Таточенко, И. Б. Волков // Педиатрия. - 2004. - № 1. - С. 58-66.

9. Резолюция XIV конгресса Педиатров России с международным участием «Актуальные проблемы педиатрии" // Российский педиатрический журнал. 2010. - № 3. - С. 61.

10. Розинова Н. Н. «Трудный пациент» Клинические формы хронических воспалительных заболеваний лёгких у детей: критерии диагностики и принципы терапии // Тер. архив. - 2007. - № 10.

11. Шамсиев Ф. М. Структура заболеваемости органов дыхания в регионах республики / Ф. М. Шамсиев, У. А. Каримов, Н. Д. Азизова // Вестник врача общего профиля. - 2004. - № 4 (32). - С. 113-115.

12. Primary ciliary dyskinesia, immotile cilia syndrome, and Kartagener syndrome: diagnostic criteria / V.H. Dombi, H. Walt // Schweizerische Medizinisch Wochenschrift. J. Suisse de Med. -1996. - Vol. 126, № l. - P. 421-433.

13. Kitz R. Immunoglobulin levels in bronchoalveolar lavage fluid of children with chronic chest disease / R. Kitz // Pediat. Pulmon. - 2000.

\section{TREATMENT OF CHILDREN WITH CHRONIC BRONCHITIS}

\section{@A. M. Shamsiev, L. A. Mukhamadieva, Sh. A. Yusupov, D. T. Rabbimova Samarkand State Medical Institute}

SUMMARY. For the improvement of the treatment results of children with chronic bronchitis 27 children with chronic bronchitis and 22 healthy children from control group have been investigated. Children with chronic bronchitis during bronchoscopy have unaergone autotransplantation of macrophage tissues of the respiratory tract with stimulation by polyoxydonine. The effectiveness of such method has been proved by the results of the improvement of the indexes of the lavage fluid and immunological status of children before and after treatment.

KEY WORDS: endobronchitis, polyoxydony, alveolar macrophages immunoglobulins, lymphocytes.

Отримано 06.11.2015 